\title{
La conflictividad en torno al pago de la renta foral en Galicia a finales del antiguo régimen
}

\author{
M. CONCEPCIÓN BURGO
}

Uno de los problemas fundamentales con el que tienen que enfrentarse las instituciones monásticas -como cualquier institución rentista-, es el de la deuda derivada de los impagos de las rentas sobre las que se sustenta su economía. Este es, para ellas, un problema crónico que afecta a todos sus ingresos; pero no por ser crónico es inmóvil, la deuda se agudiza en determinados momentos fruto, fundamentalmente, de una coyuntura adversa.

Es obvio que las primeras y más evidentes repercusiones de la deuda se producen sobre la evolución de los ingresos, a un doble nivel: a corto plazo retrasando la llegada de las rentas anuales y retrayendo, por lo tanto, una parte de sus ingresos, pero también a largo plazo, porque la institución puede llegar a perder una parte de sus rentas ${ }^{1}$.

Universidad de Santiago.

1 No es nuestra intención realizar un estudio de profundidad de estos problemas, por ello valgan tan sólo unos ejemplos que confirman lo que decimos: durante el siglo XVIII, en períodos normales, la deuda retrae, en el monasterio de San Payo, la cuarta parte de la renta teórica, que se pagará, al menos en parte, con retraso. En los períodos de crecimiento de los impagos, la deuda puede llegar a afectar al 50 por 100 o más de la renta. Gran parte de las deudas son efectivamente cobradas, pero otra parte se perderán irremisiblemente. Por ejemplo, en el conjunto del siglo XVIII, se pierden por impagos el 3 por 100 de la renta teórica, pero esto encubre grandes diferencias: en la década de 1710 la casa no recibe el 8 por 100 de su renta, en $1720-29$ el 7 por 100 , en la década 1760 el 10 por 100 . Remitimos a nuestra tesis doctoral, C. BURGo LOPEz: Un dominio monástico femenino en la Edad Moderna. El monasterio benedictino de San Payo de Antealtares. 1986. pp. 925 y ss. 
Pero hay que establecer matizaciones más precisas. La deuda incide sobre todos los ingresos monásticos -en este caso del Monasterio de San Payo de Santiago, cuyos fondos documentales vamos a utilizar en este trabajo-, arrendamientos del cobro de rentas territoriales y diezmos que se efectúan para recaudarlas en algunos períodos de tiempo, réditos de los censos comprados y rentas agricolas ${ }^{2}$, pero las repercusiones cuantitativas y cualitativas que tiene cada tipo de deuda sobre la economía monástica, y las soluciones posibles son diferentes. Los ingresos fundamentales del monasterio de San Payo -al igual que los de todo el clero regular gallego - son las rentas agrícolas derivadas de la cesión de una amplia propiedad territorial, fundamentalmente bajo la forma de contrato de foro, que suponen para el conjunto del siglo XviII el 69 por 100 de los ingresos totales. Son, por lo tanto, los impagos de renta foral los que tienen una mayor incidencia sobre la economía del cenobio. Por otra parte, la deuda de renta foral presenta una problemática diferente, de mayor trascendencia a largo plazo que cualquier otro tipo de deuda, porque esta íntimamente ligada a la ocultación y encubrimiento de la propiedad. En efecto, confusión de la propiedad y pérdida de renta son conceptos unidos, porque el cobro de la renta foral es tanto una consecuencia de detentar el dominio directo, como una prueba justificativa de la propiedad. Por ello, si los foreros del monasterio cuestionan el pago de las rentas, y se resisten a ello, se está cuestionando, en última instancia, la propiedad territorial del cenobio, el cual se veria, en general, en graves problemas para probar sus derechos judicialmente. No es extraño, pues, que la renta foral - junto con la defensa de la propiedad-, resulte ser el foco de atención primordial de los dirigentes del monasterio, y que a su alrededor giren los mayores confictos entre el monasterio y los beneficiarios de su dominio territorial.

Pero estos conflictos no se mantienen inalterables ni en su forma ni en su naturaleza. A finales del Antiguo Régimen se observan cambios importantes en lo que había sido la tónica general, que repercuten en la

${ }^{2}$ El monasterio de San Payo posee otros ingresos pero de poca importancia económica: educaciones - cantidades pagadas por el mantenimiento de niñas en el cenobio a cargo de religiosas de la familia- o rentas derivadas de la cesión de unos cuantos inmuebles. Un ingreso muy importante lo constituyen las dotes de entrada, pero aquí el problema de la deuda es pequeño y se solventa personalmente con las familias.

Las rentas principales provienen de la cesión de la propiedad territorial, que a efectos de administración se encuentra dividida en prioratos dirigidos individualmente por monjes de la Orden con el título de prior. Ibidem. 
economia del monasterio y dan lugar a unas tensas relaciones entre el cenobio y buena parte de sus foreros.

\section{CONFLICTIVIDAD EN TORNO AL PAGO DE LAS RENTAS EN EL SIGLO XVIII}

Durante buena parte de este siglo no se producen graves problemas en torno al pago de la renta foral. Existe, obviamente, una deuda inevitable unida a la marcha de la coyuntura agrícola de la que, en general, se ocupan los priores encargados de la administración. La casa central sólo actúa judicialmente cuando las deudas se acumulan y llegan a un cierto nivel. La cronología de estos memoriales de deudores de rentas forales, que eleva el monasterio ante la Audiencia, indican que las deudas se incrementan en momentos determinados. Por una parte en las décadas 1720 y 1730. Esta última parece ser especialmente dificultosa en la zona Sur de la provincia de Lugo, a tenor del número de memoriales presentados ${ }^{3}$. En las décadas centrales del siglo la deuda disminuye: no encontramos nuevos memoriales hasta $1760 / 70^{4}$. El problema de los impagos en los prioratos vuelve a recrudecerse en el último período del siglo, y como respuesta, en 1804, se eleva un memorial de deudores que cubre más de ocho años ${ }^{5}$. Pero lo que nos interesa destacar no es este acercamiento, claramente grosero, a la evolución cronológica de la deuda, sino que este problema no provoca conflictos graves ni generalizados entre el monasterio y sus foreros durante la mayor parte del siglo. De hecho, y como prueba de ello, la actitud del cenobio - salvo en casos particulares-, no es dura ni de presión inmediata sobre los deudores, sino todo lo contrario. La casa central sólo se dirige hacia los tribunales cuando las deudas se han acumulado cinco o seis años, presta granos

3 Por ejemplo, entre otros, en 1729 se presenta en la Audiencia, un memorial de deudores del priorato de Camanzo (norte de Pontevedra), que incluye impagos forales producidos entre 1725 y 1729. Archivo Histórico de la Universidad de Santiago, Bienes Nacionales (en adelante A.H.U.S., B.N.), Leg. 841, fs. 240-251. En 1735 se presenta otro con deudas forales registradas en el priorato de Cangas (sur de Lugo), que se repite en 1740 , por impagos producidos desde 1730. En 1741 se presenta una petición de apremio contra deudores del priorato de Lobios - cercano al anterior-, con impagos registrados desde 1732. A.H.U.S., B.N., Legs. 855 y 856.

4 A.H.U.S., B.N., Leg. 856.

${ }^{5}$ Ibidem, Leg. 901 
a sus colonos, concede moratorias en el pago y perdona parte de la renta cuando la situación agrícola es adversa ${ }^{6}$. $Y$ todo indica que presiona en mayor medida a la hidalguía que a los campesinos ${ }^{7}$, lo cual se debe, indudablemente, a que es la hidalguía intermediaria la que se muestra más activa en el encubrimiento del dominio directo del monasterio. Con los campesinos sólo se encuentra una postura intransigente, llegando al embargo de los bienes cuando, y significativamente, éstos no reconocen la deuda ni la propiedad de San Payo, no siendo ésta, por otra parte, la postura mayoritaria ${ }^{8}$. Pero durante la mayor parte del siglo XVIII, y esto es lo más destacable, no hemos encontrado rastros de resistencias abiertas de los foreros al pago de las rentas, ni de alteraciones graves en los prioratos. Esta situación parece cambiar ya en las últimas décadas del siglo. A partir de 1780 comenzamos a asistir a la aparición de algunos conflictos en los prioratos, con enfrentamientos graves entre los priores y los colonos motivados por múltiples causas, pero teniendo como elemento común problemas en torno al cobro de las rentas. Pueden ser, obviamente, conflictos personales, debidos a la mala gestión de algún encargado, y de hecho no encontramos indicios de una resistencia abierta al pago de la renta, pero representan el primer elemento de una incomodidad, por el momento aislada, que constituye un precedente de los conflictos que surgen en el siglo xix, y en todo caso una muestra de que la situación anterior comienza a deteriorarse ${ }^{9}$. Por

${ }^{6}$ Los préstamos de grano parecen ser una práctica habitual dado que aparecen frecuentemente en los memoriales deudas por este concepto. Ibidem, Leg. 856 por ejemplo. Los perdones de renta en momentos de malas cosechas son muy frecuentes, por ejemplo en los años finales de la década de 1780 y en los primeros de la siguiente, se suceden en todos los prioratos. Ver Archivo del Monasterio de San Payo (en adelante A.S.P.), entre otros los Legs. C-13 y C-15. En cuanto a las moratorias ver, por ejemplo, A.S.P. Leg. C17.

7 Ver, por ejemplo, el memorial de deudas del priorato de Cangas de 1764 . Hay un gran número de hidalgos encausados, y las diligencias realizadas con ellos cubren la mayor parte de los autos. A.H.U.S., B.N., Leg. 856, sin $f^{\circ}$.

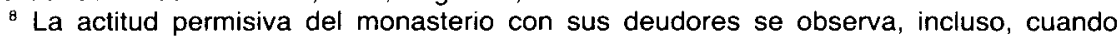
se ha puesto en marcha todo el aparato judicial. Por ejemplo, en 1768 comenzaron las diligencias sobre una demanda de impagos de foreros del priorato de Cangas. Poco tiempo después, el prior ordena al escribano que cese en las notificaciones porque "todos habian concurrido a pagar según sus posibilidades" y había decidido darles algún plazo más. En 1769, el mismo prior eleva la petición de que se embarguen judicialmente los bienes de Amaro de Bouzas, para ordenar de nuevo que cese el embargo "ya que las súplicas le mueven a la compasión" y le da otro plazo "viendo sus necesidades y la esterilidad del año". Sólo se actúa en serio cuando los deudores comienzan a vender los bienes. A.H.U.S., B.N., Leg. 856.

9 Entre los ejemplos más significativos: los foreros de Lobios acusan al prior en 1781 , de cobrar dos o más veces la misma renta. Al prior de Lobanes se le acusa de cobrar injustamente laudemios y luctuosas. A.H.U.S., B.N., Leg. 907. En otro priorato, Camanzo, 
otra parte, en estas últimas décadas la deuda asciende, aunque todavia no puede considerarse muy grave su incidencia dentro del conjunto de los ingresos. Sí se puede considerar así la deuda que se acumula desde 1808 , y sobre todo después de 1811 , pero aquí la situación ya es muy distinta.

\section{CONFLICTIVIDAD EN TORNO AL PAGO DE LA RENTA A FINALES DEL ANTIGUO REǴIMEN}

Desde 1811-12 los foreros de varios prioratos de San Payo se niegan formalmente a pagar las rentas amparándose en el Decreto de 6 de agosto de 1811 que suprime los señoríos jurisdiccionales. La resistencia abierta no se generalizó a todos los anexos del monasterio, pero sí a un número importante: desde 1811-12 aparece en los prioratos de Ramiranes, Sobrado y su anejo Sta. María de Coba (provincia de Orense) y en el de Lobios (sur de Lugo), en el Trienio se extiende a los de Albeos (suroeste de Pontevedra) y Chouzán (sur de Lugo), aunque con fuerza e intensidad diferente. La relación que establecen, en todos ellos, los foreros entre el pago de las rentas forales y la posesión del derecho jurisdiccional es muy clara: los vecinos de Ramiranes se niegan a pagar las rentas forales al monasterio hasta que "se les muestren los papeles originales porque las cobraba", e interponen una demanda de título ante el juez del coto que también es forero de San Payo ${ }^{10}$. Los vecinos de Sobrado de Trives se niegan a pagar la renta desde $1812 \mathrm{y}$, al conseguir el monasterio despachos en la Audiencia para ejecutar a los deudores, acuden, en 1815, al Consejo Supremo de Hacienda presentando una demanda de tanteo a la jurisdicción y rentas. Las anotaciones de un vicario sobre las causas de la actitud de los foreros son muy significativas: han puesto la demanda "persuadidos los vecinos de que entrando en el goze de la jurisdicción se hacian también dueños de las tie-

\footnotetext{
los problemas son más virulentos, llegando a recibir el prior anónimos que le amenazan de muerte. Una de las reivindicaciones es que prescinda de los escribanos que le ayudan a recaudar las rentas. La amenaza de muerte no llegó a cumplirse, pero en su lugar le quemaron el hórreo. A.S.P., Leg. C-13.

${ }_{10}$ A.S.P. Leg. A-18, Libro de Pleitos y Leg. A-13, Cartas privadas, 13-XI-1814, 3-II1815 del prior de Ramiranes.
} 
rras..." ". Los foreros de Santa María de Coba basan su resistencia en que compraron el señorío jurisdiccional a Felipe II, y que, por tanto, están exentos del pago de cualquier renta ${ }^{12}$. En el Trienio se recrudecen las resistencias en estos anexos, interponiendo los foreros nuevas demandas contra San Payo, al mismo tiempo que se extienden a otros prioratos bajo los mismos supuestos ${ }^{13}$. En Albeos los vecinos se escudan en el Decreto dado por las Cortes del Trienio, que declara abolido el pago de todas las prestaciones de origen feudal, exigiendo la presentación de títulos por parte de los señores para determinar la naturaleza de los derechos, aunque el veto del rey impedirá su promulgación hasta la víspera de la invasión francesa ${ }^{14}$. Amparándose, a pesar de ello, en este decreto, el 15-8-1821 "un abogado de este partido, que en la actualidad es Alcalde Constitucional, mandó convocar todo el vecindario de su alcaldia... y les propuso que todos podían y debian dar poder a uno o dos paysanos para notificarme a mi (el prior) o a Vmd. en Santiago que para las rentas del año 21, no presentando el monasterio de San Payo los títulos primordiales de la adquisición de estas haciendas nadie pagase renta ni pensión a las Sras. ${ }^{15}$. En 1823 todavía no se había cobrado nada en este priorato. En el anexo de Chouzán la resistencia se basó en el mismo Decreto: el alcalde constitucional tomó, en nombre de los vecinos, los bienes del monasterio, pero una orden del Intendente los devolvió a las religiosas, siendo aquí la contestación al pago menos aguda que en los restantes anexos afectados ${ }^{16}$.

Los cabecillas de estas resistencias pertenecen a grupos muy concretos, al menos según la versión de las religiosas. Son alcaldes constitucionales como en Albeos o Chouzán o clérigos como en Sobrado, donde los foreros se niegan a pagar las rentas porque "el abad de San Mamed, D. Juan Rivera... se propuso y le fue fácil fascinarlos, alucinarlos

"A.S.P. Leg. A-18, Fs. 50 r. y 51

12 Ibidem f. 57.

${ }^{13}$ Los vecinos de Sobrado detuvieron el pleito de tanteo durante un tiempo y lo reanudaron en 1822. A.S.P. Leg. A-18.

${ }_{14}$ M. ARtola: La burguesia revolucionaria (1808-1874), Madrid 1978, pp. 48 y ss. Y Los origenes de la España contemporánea, t. I, Madrid 1975, p. 550.

15 A.S.P. Leg. A-13, 1

${ }^{16}$ En este priorato, el 8 de noviembre de 1820 , el Alcalde Constitucional "en unión con los demás individuos de aquel ayuntamiento y auxiliado de una multitud de gente de aquellas immediaciones, sorprendió al prior administrador y con el mayor imperio se entró en la casa, se apoderó de las llaves del archivo, de las de los graneros... poniendo todos los frutos al cargo de depositarios... (dejando) a esta comunidad privada de precibir el pequeño rédito que le producia el priorato...” A.S.P., Leg. C-31. 
e inducirlos con firme propósito a la tal resistencia, persuadiéndolos de que así se hallaba determinado y resuelto por Real Decreto del 6 de agosto de $1811 \ldots$.. Su más activo colaborador es también un clérigo, $D$. Juan Losada ${ }^{17}$. El protagonismo de los sacerdotes en Trives continúa durante el Trienio, en este momento es D. Domingo López «uno de los enemigos más capitales que tenemos...», y que todavia en 1827 sigue planteando problemas a la comunidad que pide ayuda al Capitán General para expulsarlo de Sobrado. Los calificativos que aplican los administradores de San Payo a estos individuos resultan muy gráficos: para ellos son unos "anti-clérigos", unos "amantes de la Constitución" y además unos "sansculotes", epiteto preferido del prior de Ramiranes.

Lo que resulta difícil de discernir es si la confusión entre rentas forales y rentas jurisdiccionales es una táctica de los foreros 0 una confusión real. M. Artola ha puesto de manifiesto la ambigüedad del decreto de abolición, al no distinguir claramente derechos jurisdiccionales, solariegos y contractuales, y las consecuencias que esto trajo para su aplicación y para muchos propietarios castellanos. De la misma forma el decreto no delimita con claridad $-y$ en esto se centraron muchas de las controversias- quién tenía que probar su alegato: los señores presentando los títulos de propiedad, o los pueblos. Al final quedó al arbitrio de los tribunales la aplicación del decreto ${ }^{18}$. $Y$ aqui radica uno de los problemas fundamentales de los señores, en este caso del monasterio de San Payo, que se vería en grandes dificultades para probar documentalmente sus derechos y propiedad. Esto se observa claramente en el pleito que mantiene con los vecinos de Sobrado, que, como ya dijimos, en 1815 ponen una demanda de tanteo a la jurisdicción y rentas. El Consejo de Hacienda ordenó a San Payo presentar documentos acreditativos de su propiedad, pero el monasterio no logró encontrar ninguno con verdadera importancia. Después de quedar el pleito en suspenso durante algún tiempo, fue movido de nuevo por los procuradores del monasterio, "viendo el buen éxito que habian tenido otras demandas puestas contra Samos, Poyo y Tenorio" (todos monasterios benedictinos), pero el dictamen del fiscal no fue muy favorable. Reconoce el derecho de los vecinos al tanteo, debiendo pagar estos 5.500 ducados, que aprontaron más

\footnotetext{
${ }_{17}$ Memorial de varios terratenientes y administradores de la región, entre ellos Fray Anselmo Godinez, prior de Trives al Comandante General de Galicia. A.S.P., Leg. C.57.

${ }^{18}$ M. ARTOLA: Los Orígenes..., op. cit. pp. 546-549. La burguesia, op. cit. pp. 37 y 131 ss
} 
tarde en vales reales ${ }^{19}$. Pero San Payo va a continuar el pleito porque, en palabras del vicario "aunque en la actualidad tenemos ya perdida la jurisdicción con las rentas a ella anexas, conviene sostenerlo con empeño, no sólo por lo que pueda suceder en adelante, sino porque están persuadidos los vecinos de que el dominio territorial provino de la jurisdicción y que está anexo a ella dándonos mucho que hacer probar lo contrario... lo que convendrá tener presente para el caso de que nos manden presentar los títulos primordiales..." ${ }^{20}$. Pero estos títulos nunca fueron pedidos. En los periodos absolutistas la cuestión de quien debía probar su derecho quedó en suspensión, y en 1837 se dictaminó en favor de los señores ${ }^{21}$. Además en todos estos años los tribunales - luego lo veremos- fueron favorables al monasterio, lo que evitó la pérdida de la propiedad.

Retomando la primera pregunta, es difícil saber con exactitud si la confusión es un subterfugio o es real. En el caso de Sobrado, los colonos parecen creer firmemente que las rentas forales derivan de la jurisdicción, en los restantes es más dificil llegar a una conclusión; más parece un subterfugio que una confusión, sobre todo teniendo en cuenta que en Galicia es más evidente que en otras zonas, la disociación entre señorio solariego y jurisdiccional ${ }^{22}$. Por otra parte, el monasterio nunca hizo fuerza en estos prioratos, para seguir cobrando sus derechos jurisdiccionales, fundamentalmente luctuosas y abadías, ni intentó confundir estas rentas señoriales con las contractuales. El pago de estos derechos nunca formó parte de las controversias entre foreros y monasterio.

Pero creemos que es más importante constatar que, con subterfugio o sin él, la oposición al pago de las rentas se generalizó a la práctica totalidad de los foreros de estos prioratos, y dada la estructura de los dominios monásticos gallegos, con una propiedad muy dispersa, esto afecta a gran número de parroquias: 17 en el caso de Sobrado, 16 en el de Ramiranes, todas ellas en la provincia de Orense, 18 en Albeos (Pontevedra), aunque las resistencias más activas las ofrecen los foreros de las parroquias donde se sitúan las jurisdicciones de San Payo, lo que

\footnotetext{
19 A.S.P. Leg. A-18. La cantidad es la misma que pagó San Payo a Felipe II para evitar la desmembración de este coto.

${ }^{20} \mathrm{lbidem}$, fs. 50-51.

${ }^{21}$ M. ARtOlA: La burguesia..., op. cit., p. 131.

22 P. SaAvedra: Economía, Política y Sociedad en Galicia: La provincia de Mondoñedo, 1480-1830, Santiago 1985, pp. 630-634. R. VILLARES: La propiedad de la tierra en Galicia, 1500-1936, Madrid 1982, p. 146.
} 
resulta lógico dadas las caracteristicas de la contestación, pero que se debe, también, a que es en estas feligresías donde se concentra la mayor parte de la propiedad y de la renta de cada priorato. Si analizamos las cantidades de renta impagadas, se puede ver la expresión de la resistencia así como la repercusión que tiene sobre la economía del cenobio:

En Sobrado, con unas rentas forales de 25 moyos de vino, 334 ferrados de trigo y 2.917 ferrados de centeno al año, de 1812 a 1814 se dejan de pagar anualmente las cantidades siguientes:

10 moyos de vino $40 \%$ de la renta.

310 ferrados de trigo $93 \%$

De centeno en 1812 no pagaron 1.712 ferrados $58,7 \%$ 1813 no pagaron 2.788 ferrados $95,6 \%$ 1814 no pagaron 2.615 ferrados $90 \%$

Estos porcentajes abrumadores del 93 por 100 de la renta anual de trigo y 95,6 por 100 de centeno, que no puede ser cobrada en 1813 , no deja lugar a dudas sobre la extensión de la resistencia, al mismo tiempo se puede observar cómo ésta crece al calor de la misma fuerza de la contestación y de la incapacidad del monasterio para responder en los primeros momentos.

En el priorato de Ramiranes se observa este mismo crecimiento de la resistencia, pero con la salvedad de que aquí es mucho más aguda, recorriendo la práctica totalidad del período absolutista del 14 al 20. Con unas rentas forales anuales de 11 ferrados de trigo, 350 de menudos y 1.315 de centeno, entre 1811 y 1813 se deja de pagar al año lo siguiente: 
la totalidad del trigo (hasta 1827).

214 ferrados de menudos .... $61 \%$ de la renta anual.

820 ferrados de centeno ..... $62 \%$

A partir de 1814 las cantidades no pagadas crecen, continuando la resistencia. Según un memorial de prior, los foreros deben en total de los años 1814,1815 y 1816 lo siguiente:

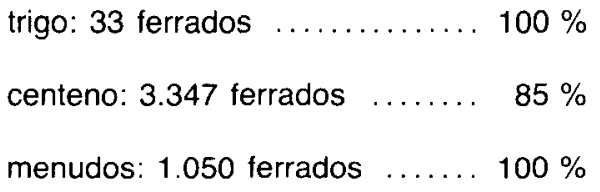

A partir de esta fecha siguen siendo negados 1.115 ferrados de centeno hasta 1824 , y entre un 75 por 100 y un 80 por 100 de los menudos.

En Santa María de Coba, donde la renta foral asciende a unos 500 ferrados de centeno anuales, no se pudo cobrar nada entre 1812 y $1823^{23}$. La situación en el priorato de Albeos es muy semejante: oponiéndose los foreros al pago en 1821, todavía en 1826 no se han podido cobrar las rentas de 1821,1822 y 1823 , ascendiendo la deuda en total a las siguientes cantidades: ${ }^{24}$

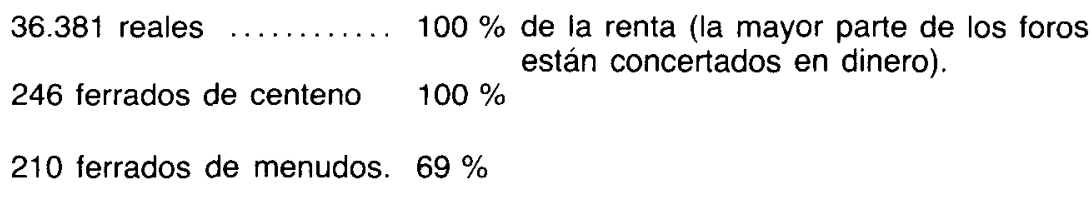

23 A.S.P. Legs. C-55, C-41, A-11. Los renteros del priorato de Lobios también se niegan a pagar la renta entre 1811 y 1814 , pero no sabemos a cuanto asciende la deuda, sólo que el prior se gastó en $1814,2.040$ reales "por diligencias hechas y salarios, con los foreros que se negaban a pagar» A.S.P. Leg. C-37.

24 A.S.P. Leg. C-41. 
Como respuesta a este problema, el monasterio acude a los tribunales, fundamentalmente a la Real Audiencia, que mantuvieron, incluso en los períodos liberales, una actitud favorable al cenobio. Ninguno de los pleitos incoados por los vecinos fue ganado al final por ellos, y todos los tribunales, la Audiencia, la Chancillería o el del Consejo de Hacienda, ampararon el derecho de San Payo. En la Audiencia, el monasterio solicitó y consiguió numerosas provisiones para ejecutar a los deudores, primera de las armas utilizadas para atajar la pérdida de ingresos. Aunque con ellas se consiguieron cobrar algunas rentas en los prioratos más conflictivos, la medida fue poco efectiva porque los foreros siguieron oponiéndose al pago con argucias de todo tipo. En Ramiranes muchos negaron haber pagado en alguna ocasión al monasterio, otros afirmaron desconocer la cantidad que debian pagar. En Sobrado el vicario afirma que «habiéndose sacado despacho para diligenciar a los deudores... estos se propusieron burlarse de los mandatos del tribunal adoptando el medio malicioso de ocultarse cerrando las puertas y huyendo a los montes cuando veian al escribano para no ser diligenciados... "25. Pero la respuesta más cotidiana de los deudores frente a estas diligencias, y también la más generalizada, fue la violencia, con amenazas a los ejecutores y priores, y llegando incluso a la acción directa, síntoma claro de la gran crispación existente, durante este período, en el mundo rural. Los ejemplos son múltiples porque la violencia aparece en todas partes: en Sobrado, en 1815 cuando se están realizando cobros con despachos de la Audiencia, los deudores para intimidar al escribano y uhacer que abandonase su comisión se reunian por la noche a las puertas del priorato gritando fuera el executor y amenazándole de muerte sino se iba dentro de 24 horas, previniendo y amenazando a los deudores si se presentaban a declarar, a los que habian confesado si pagaban y al juez porque había dado uso... ${ }^{26}$. En 1821, el prior de Ramiranes afirma que no adelanta en las cobranzas porque todo son «alaridos y quexas y execraciones contra mi, escribano y ministro... y aún más la noche del 16 que me apedrearon las vidrieras de mi cuarto..." Un mes mas tarde afirma que los deudores le amenazan "con suma libertad que me han de quemar la estatua, casa y papeles... ${ }^{27}$. En 1824 , en Sobrado, los foreros interponen una demanda contra el ejecutor "sólo por entorpecer las cobranzas...", según el prior, "y ese mismo día se levantó un motín contra el executor que por una casualidad dejó de parecer...». Al mes siguiente

\footnotetext{
25 A.S.P. Leg. A-18, fs. 48-52.

${ }^{26}$ lbidem, f. 49.

${ }^{27}$ A.S.P. Leg. A-13, 1. 20-VIII y 22-IX-1821.
} 
el prior afirma que ha sido asaltado por una partida de hombres «que me maltrataron con muchos golpes y lo mismo al escribano que tenía en casa atendiendo en las ejecuciones, con que ambos nos hallamos en cama... ${ }^{28}$. Es significativo el hecho de que la violencia aparezca también en prioratos donde no se registran resistencias formales al pago, como por ejemplo en Lobanes (Noroeste de Oreste), donde el prior, en 1820, mandó "venir al Ministro para avisar a algunos deudores y el resultado ha sido darle de pedradas, acusarle al juez y amenazarle a el y a mi con el Corregidor de Carballino... " $"$. Todo parece indicar que estas tensas y violentas relaciones entre dominio directo y foreros son una constante hasta la desamortización: Todavía en 1828 la abadesa afirma que en la feligresia de Villameá (priorato de Ramiranes), "se ha maltratado gravemente a Jacinto Feijoo, ministro que auxilia al Receptor que atiende en los prorrateos, por sólo el motivo de haber ido a dar aviso a algunos colonos que fuesen a pagar la renta al Priorato ${ }^{30}$ ".

A esta situación contestó el monasterio también con violencia, recurriendo al Capitán General de Galicia para utilizar la fuerza del ejército en las cobranzas, al menos a finales de la década de 1820. En alguna ocasión le fue concedida esta ayuda militar: el 5 de mayo de 1827, la abadesa escribe al Capitán General agradeciéndole la ayuda que le está prestando en Ramiranes, "cuyos colonos tercos y obstinados se empeñaban en no pagar la renta... más V.E. adoptando medidas enérgicas se habrá convencido de su mala fe... y que tales gentes no se mueben ni entran en vereda sino por medio del rigor..." y pidiendo que la auxilie también en las cobranzas de Sobrado ${ }^{31}$. Aunque hay que anotar que el ejército sólo fue utilizado en los prioratos más conflictivos. Nunca se tomaron estas providencias contra los deudores de otros anexos.

Otra de las medidas tomadas por el monasterio fue la realización de prorrateos en los prioratos donde no se reconocía la deuda y la renta estaba "obscurecida", situación que por lo demás no es nueva, sino que viene de atrás. Pero también para esto San Payo encontró muchas dificultades, al menos según la versión de los priores. El 20 de julio de 1820 se despachó por la Audiencia la provisión para hacer prorrateos en Ra-

${ }^{28}$ Ibidem, abril y 22 de julio de 1824 .

29 A.S.P. A-13, 2.

${ }^{30}$ A.S.P. Leg. A-11, Varios, 7.

${ }^{31}$ El 25 de mayo de 1827 la abadesa vuelve a pedir ayuda al Capitán General para realizar las cobranzas en Sobrado. Ibidem. 
miranes, pero en un año sólo se consiguió hacer seis, porque "cada paso en dichos rateos es un tropiezo y lo peor de todo es que están tan obcecados $y$ reunidos en resistir $y$ hacer frente al directo dominio por tantas sofisterias, intrigas y cabilaciones que yo me persuado... nos tendrán empantanados para dichos prorrateos cien años... todo procede de su mala fe y de la convención general que se halla en ellos de no descubrirse ni servir de testigos los unos a los otros" ${ }^{32}$. En realidad, en 1828 aún se seguía con los prorrateos ${ }^{33}$.

Como podemos observar, a pesar de que el monasterio tiene el apoyo de los tribunales para realizar el cobro de las rentas contestadas, a nivel práctico los logros son muy escasos, resultándole muy difícil imponerse durante un largo período de tiempo a los foreros. Por ello hay otro aspecto a considerar en estas alteraciones. La pérdida de la jurisdicción y con ella la facultad de nombrar a las justicias locales, tiene incidencia en el cobro de las rentas, y en el hecho claro de que el dominio directo está incapacitado para hacerse obedecer, situación que tiene que afectar a todos los prioratos donde San Payo poseía la jurisdicción y no sólo a los más conflictivos ${ }^{34}$. La importancia de las justicias locales en todos estos problemas que estamos tratando se manifiesta con claridad. Con una justicia local hostil, al monasterio le resulta difícil imponer sus derechos y realizar las cobranzas, cuando le es favorable el cobro de las pensiones se hace más fácil. Algunos ejemplos servirán para comprobarlo. En 1823, la abadesa escribe al Regente de la Audiencia afirmando que en Santa Maria de Coba la comunidad no cobra sus rentas forales desde el Decreto de Señoríos, "no obstante las varias providencias de Vra. Real Audiencia... haciendo inútiles dichos vecinos dichas providencias sin gastar un solo cuarto, solo con denegarse la justicia ordinaria a darles el uso, añadiendo amenazas de muerte e insultos a los executores que con razón no quieren exponer su vida...». San Payo consiguió una providencia de este tribunal «para que se reprendiese al juez... allanándose el juez a obedecer en adelante... pero llegado al pueblo volvió a su tema de no obedecer y amenazar a los executores..." ${ }^{35}$. $Y$ este no fue

32 10-XI-1819. A.S.P. Leg. A-11, 1.

${ }^{33}$ lbidem. En Sobrado también se realizan prorrateos, y en 1821 el prior de Albeos sostiene la necesidad imperiosa de realizarlos en este anexo.

${ }^{34}$ En la jurisdicción de Sobrado de Trives, la abadesa tenía la facultad de nombrar merino y dos regidores en el concejo; en la de Ramiranes al merino, y escribano además de un juez anual que elegía entre cuatro propuestos por los vecinos, en las restantes jurisdicciones, 13 en total, que afectan a cerca de 30 feligresias, la abadesa nombraba, al menos, al juez y escribano. C. Bungo: Un dominio..., op. cit.

${ }^{35}$ A.S.P. Leg. A-11, 7 y A-18. 
el único problema que ocasionó al monasterio la acción de las justicias locales. Los vecinos de Sobrado de Trives volvieron a reanudar, en 1822 , el pleito de tanteo a la jurisdicción y rentas que habían iniciado en 1815, y habiendo pagado en vales los 5.500 ducados establecidos, solicitaron en Madrid la carta ejecutoria, con pedimento de que se les diese la jurisdicción y las rentas. Según afirma la abadesa, «el juez de primera instancia puesto en aquella jurisdicción por el gobierno intruso, sin más mérito que el de filósofo, pues las leyes no han sido su estudio... les dio la posesión, no sólo de la jurisdicción sino de las rentas territoriales... que aunque este último atontado espera la Comunidad lo revoque Vra. Real Audiencia pero no los demás ni los desembolsos que han ocasionado estas oposiciones...". La revocación llegó en el período absolutista, pero los vecinos de Sobrado pidieron apelación en Valladolid y en el Consejo de Hacienda, sintoma evidente, por otra parte, de la resistencia activa de los foreros incluso en los períodos no liberales ${ }^{36}$. En el caso del priorato de Ramiranes, se afirma que la justicia local está "confabulada" con los colonos, encubriendo incluso el atentado de que fue objeto el receptor que llevaba los prorrateos en $1828^{37}$. El caso contrario, con una justicia favorable, se observa en Sobrado después de 1814: durante algunos años parece que se logró cobrar algo de la renta upor haber hallado justicia ordinaria que quiso y se hizo obedecer... ${ }^{38}$. En definitiva, creemos que es posible pensar que la pérdida de la jurisdicción, si bien no tiene importancia en cuanto a la supresión de unas rentas señoriales, en estos momentos sin demasiada significación económica, si hizo que el poder de la iglesia disminuyese de forma considerable.

Las cobranzas en los restantes prioratos se vieron también seriamente alteradas en el primer tercio del siglo, aunque en ellos no se registraron conflictos abiertos ni negativas formales de los colonos, pero las quejas de los priores diciendo que los foreros no pueden pagar y están pasando hambre, llegan desde todos los puntos del dominio en el último quinquenio de la década de 1810 y primeros años de la siguiente: en 1816, el prior de Camanzo (norte de Pontevedra) afirma, justificando las deudas que cademás de la suma pobreza de esta dilatada parroquia, acuérdese $V$. $P{ }^{a}$. (el vicario) del año escasísimo y hambriento del año pasado en que no sólo por caridad sino por necesidad me veía obligado

${ }^{36}$ Ibidem. t. 55 r.

37 A.S.P. Leg. A-11, 7. Carta al Capitán General.

38 Ibidem. 
a dar limosna» ${ }^{39}$. En Lobios se está padeciendo la misma situación: en 1816 el prior escribe diciendo que los vecinos "están muy miserables, dos años seguidos se les apedreó el vino y el centeno y el año pasado me vi precisado a prestarles mucho centeno, esto aún no lo pueden pagar, hasta ni siquiera pueden comer pan de cebada... Este año es mucha la miseria de este país y hay hambre...". Al año siguiente la miseria continúa. En Lobanes los problemas se suceden año tras año: en 1816 "las cobranzas están cada día de peor calidad y no es extraño porque no hay de que hacer un quarto y el ganado nada les de pero poco a poco irán pagando...", en 1817 las cobranzas también se realizaron con dificultad, en 1818 el prior afirma que "estas gentes cada vez están más rebeldes tienen distintas opiniones y forman nuevos planes para entorpecer sus pagos...", en 1820 "dan de pedradas" a un ministro que avisaba a unos deudores, en 1821 se realiza una cobranza mediana de centeno pero nada de "quartos». En Albeos, donde gran parte de los foros están concertados en dinero, se repiten situaciones semejantes: en 1818 el prior cobró poco y con dificultad, al año siguiente «ni los medios suaves ni los acres han sido bastantes para hacer cumplir su obligación y deberes a estos colonos. Me ceden posesiones para hacerme el pago $y$ es justamente lo que menos necesita el monasterio...", en 1820 el prior no ha podido cobrar la mitad de las rentas «por estar esta tierra acabada...». Por fin, en 1821, los foreros se niegan abiertamente al pago de las rentas.

La mala coyuntura agrícola que ponen de manifiesto los testimonios anteriores, es un elemento importante a tener en cuenta porque pudo actuar como factor desencadenante de las resistencias, y al menos, no cabe duda, hizo que tomasen mayor fuerza y gravedad ${ }^{40}$. Por otra parte, una más adversa situación agrícola en las zonas interiores de Lugo, Pontevedra y Orense - poco se sabe de la coyuntura agraria de estas áreas en el siglo $\mathrm{xIX}$-, que en otras comarcas gallegas podría explicar que las contestaciones del pago de la renta foral se concentren en mayor medida en el interior de la región, porque es un hecho cierto - aunque el tema necesita de mayores investigaciones- que las resistencias no las sufre

${ }^{39}$ A.S.P. Leg. A-18, 2, 24 de julio de 1816.

${ }^{40}$ Es posible que también en Ramiranes se sufriese una mala situación agricola en los años anteriores a la aparición de la resistencia abierta al pago, porque las rentas llegan con retraso a la casa central, por ejemplo en 1809 aún no se habian recibido las cantidades debidas de 1807. A.S.P. Libros de Depósito. 
tan sólo San Payo, sino que otros propietarios, tanto laicos como eclesiásticos, tuvieron que enfrentarse a problemas similares ${ }^{41}$.

Estas alteraciones en los prioratos, con sus secuelas lógicas de cobranzas difíciles, aumento de la deuda y crecimiento de los gastos en pleitos y diligencias, tuvieron un fuerte impacto sobre la economia del cenobio. Todos los ingresos procedentes de los prioratos descienden en la década de 1810, y con ellos las rentas totales con que cuenta el monasterio ${ }^{42}$, agravando las dificultades económicas que ya habian comenzado con anterioridad, motivadas por causas muy diversas que no pueden ser analizadas aquí, pero está claro que la estructura económica de las instituciones monásticas da muestras inequívocas de agotamiento décadas antes del comienzo de la desamortización.

${ }^{41}$ R. VILlares, op. cit., cita algún ejemplo, p. 55. También M. ARtola: Los Origenes, op. cit. p. 544. Ver también la referencia de la nota 17.

${ }_{42}$ Los ingresos totales llegados a la casa central desde los prioratos descienden notablemente incluso en sus cantidades nominales, durante el siglo XIX: en el quinquenio 1800 1804 se reciben como media anual algo más de seis millones de maravedis, en 1805-09 llegan anualmente unos 5,5 millones, y en el quinquenio 1815-19 ya se ha descendido a 4.333.029 marv. anuales. Lógicamente la caída en valores reales es mucho más fuerte. Ver C. BURGo: Un dominio..., op. cit. pp. 844 y ss. 